\title{
Validation of three splice donor and three splice acceptor sites for regulating four novel low-abundance spliced transcripts of human cytomegalovirus UL21.5 gene locus
}

\author{
SHUANG GAO, QIANG RUAN, YANPING MA, MALI LI, LIN WANG, BO ZHENG, \\ YING QI, YAOHUA JI, ZHENGRONG SUN and YUJING HUANG
}

Virus Laboratory, Affiliated Shengjing Hospital, China Medical University, Shenyang, Liaoning 110004, P.R. China

Received April 7, 2014; Accepted October 23, 2014

DOI: $10.3892 /$ ijmm.2014.1987

\begin{abstract}
In a previous study, one spliced transcript of human cytomegalovirus (HCMV), named UL21.5 was identified. UL21.5 has been found to be one of the viral transcripts packaged within HCMV particles. The UL21.5 mRNA is translated into a secreted glycoprotein, which is a viral chemokine decoy receptor specifically interacting with regulated upon activation normal T cell expressed and secreted (RANTES). In the present study, four novel low-abundance 3'-coterminal spliced transcripts were identified to be transcribed from the UL21.5 gene region of a low-passage HCMV strain during the late infection phase by cDNA library screening, northern blot hybridization, reverse transcription polymerase chain reaction (RT-PCR) and rapid amplification of cDNA ends (RACE)-PCR. Three splicing donor and three splicing acceptor sites found in the UL21.5 gene region were validated to be functional in an in vitro expression system. In addition, the determinant regulatory region that is necessary for the splice donor site at nucleotide (nt) 25533 was located in a 9-bp sequence around the site; the regulatory regions for the splice acceptor sites at nt 26597 and nt 26633 were located in a 20-bp sequence upstream of the site at nt 26597 and in a 10-bp sequence from nt 26641 to nt 26650 downstream of the site at nt 26633, respectively.
\end{abstract}

\section{Introduction}

Human cytomegalovirus (HCMV) is the prototype member of the betaherpesvirus family $(1,2)$. HCMV infection is generally asymptomatic in healthy individuals; however, it can cause severe disease in immunocompromised patients, such as AIDS and transplant patients (3). Congenital HCMV infection

Correspondence to: Professor Qiang Ruan or Professor Yanping Ma, Virus Laboratory, Affiliated Shengjing Hospital, China Medical University, No. 36, Sanhao Street, Heping District, Shenyang, Liaoning 110004, P.R. China

E-mail: ruanq@sj-hospital.org

E-mail: mayp@sj-hospital.org

Key words: human cytomegalovirus, UL21.5, spliced transcripts in newborns may cause multiple malformations and diseases, including jaundice (associated with hepatitis), mental retardation, blindness and deafness, involving multiple systems (4). HCMV contains a 240-kb double-stranded DNA genome which encodes over 165 open reading frames (ORFs) and several microRNAs (miRNAs) (5-10). The HCMV genome has three expression phases, i.e., immediate-early (IE), early (E) and late (L) (2).

To date, fewer than 100 predicted genes and partial gene segments have been extensively characterized with respect to their expression patterns, transcript structures and transcription characteristics (11). Some of these genes produce multiple gene products due to the alternative splicing of pre-messenger RNA (pre-mRNA) $(12,13)$. The majority of the alternatively spliced mRNA species of HCMV originate primarily, but not exclusively, from the IE gene regions. Some of the alternatively spliced variants of the IE region of HCMV have been investigated $(14,15)$. Recently, new evidence of mRNA splicing was obtained from the RL8A, UL74A, UL124 and UL150A genes (16). Alternatively, spliced mRNAs encode a number of gene products with different sizes (16).

Rawlinson and Barrell (18) found a new spliced transcript and an unspliced transcript, which were named UL21.5 $(9,10,17)$, from the complementary strand of the predicted UL21A gene of the HCMV AD169 genome during the late infection phase. UL21.5 was found to be one of the viral transcripts packaged within HCMV particles (17). The virion-associated UL21.5 mRNA is translated into a secreted glycoprotein, which is a viral chemokine decoy receptor specifically interacting with RANTES (19).

A spliced transcript that is highly homologous with the UL21.5 transcript was previously detected from a late HCMV cDNA library in our laboratory (20). In the present study, four novel low-abundance spliced transcripts, termed UL21.5 multiple spliced transcripts (UL21.5 MST), were identified to be transcribed from the UL21.5 gene region of a low-passage strain dependent upon different combinations of three splice donor sites and three splice acceptor sites. Furthermore, the splice donor and acceptor sites were validated by an in vitro transcriptional system. The necessary regulatory sequences of one splice donor site and two splice acceptor sites were also identified. 


\section{Materials and methods}

Viruses, cells and specimens. A low-passage HCMV strain $\mathrm{H}$ was isolated from a urine sample of a congenitally HCMV-infected infant at the Department of Pediatrics at the Affiliated Shengjing Hospital of China Medical University, Shenyang, China. MRC-5 and HEK293 cells were obtained from Shanghai Institute of Cell Biology and Biochemistry (Shanghai, China). The H strain was inoculated into MRC-5 cells maintained in minimal essential medium (MEM) supplemented with $2 \%$ fetal calf serum (HyClone, Logan UT, USA) and penicillin-streptomycin in an incubator at $37^{\circ} \mathrm{C}$, $5 \% \mathrm{CO}_{2}$. For HCMV IE infection, the cells were harvested at $24 \mathrm{~h}$ post-infection (hpi) in the presence of $100 \mu \mathrm{l} / \mathrm{ml}$ of the protein synthesis inhibitor, cycloheximide (Sigma, St. Louis, MO, USA). For E infection, $100 \mu \mathrm{l} / \mathrm{ml}$ of the DNA synthesis inhibitor, phosphonoacetic acid (Sigma), were added to the medium immediately following inoculation, and the infected cells were harvested at 48 hpi. For L infection, the cells were harvested at 72 hpi without any drug treatment.

HEK 293 cells were propagated in Dulbecco's modified Eagle's medium (DMEM) supplemented with $10 \%$ fetal calf serum (HyClone) and penicillin-streptomycin at $37^{\circ} \mathrm{C}$ in $5 \%$ $\mathrm{CO}_{2}$.

RNA preparation. Total RNA was isolated from HCMV H-infected and uninfected MRC-5 cells using TRIzol reagent (Invitrogen, Carlsbad, CA, USA). To remove contaminating DNA, the extracted RNA was treated with DNA-free reagent (Ambion, Austin, TX, USA). The quantity and purity of the RNA preparations were estimated by optical density value detection.

cDNA library screening. A full-length cDNA library of the HCMV H strain was previously constructed using the pBluescript II SK vector (20). Recombinants of the cDNA library were transferred into the E. coli JM109 strain (Promega, Madison, WI, USA). A total of 8,600 cDNA clones were randomly selected and inoculated into LB medium. A pair of specific primers for the UL21.5 gene region (R-s3 and 5'R3) (Table I and Fig. 1) were designed and used to screen UL21.5 genespecific clones from the cDNA library by graded polymerase chain reaction (PCR) as described in previous studies $(21,22)$. The PCR reaction conditions were as follows: $95^{\circ} \mathrm{C}$ for $5 \mathrm{~min}$, 30 cycles of $95^{\circ} \mathrm{C}$ for $45 \mathrm{sec}, 56^{\circ} \mathrm{C}$ for $45 \mathrm{sec}$ and $72^{\circ} \mathrm{C}$ for $30 \mathrm{sec}$, followed by a final elongation at $72^{\circ} \mathrm{C}$ for $10 \mathrm{~min}$. Inserts of the selected clones were sequenced using the vector primers, M13F and M13R, on an ABI PRISM 3730 DNA analyzer (Applied Biosystems, Foster City, CA, USA). The screening results allowed us to obtain cDNA clones containing sequences between the screening primers from both genome strands.

Northern blot analysis. Northern blot analysis was performed using the digoxigenin (DIG) system (Roche Diagnostics, Indianapolis, IN, USA) according to the manufacturer's instructions. Initially, the same amount of IE, E and L RNA preparations of the HCMV H strain and RNA from uninfected MRC-5 cells (10 $\mu \mathrm{g}$ RNAs in each lane for detection by probe 1 , and $5 \mu \mathrm{g}$ RNA in each lane for detection by probe 2 and UL99 probe) were subjected to denaturing agarose gel $[1.5 \%(\mathrm{wt} / \mathrm{vol})]$ electropho- resis in the presence of formaldehyde along with the DIG-labeled RNA molecular weight marker I (Roche Diagnostics). The probes were synthesized and labeled using a DIG Northern Starter kit (Roche Diagnostics) and primers 21.5-NS1 and 21.5-NAS1, 21.5NS2 and 21.5-NAS2, as well as 99-NS and 99-NAS. The primers were designed according to the sequences of the transcripts identified by cDNA library screening, the UL21.5 transcript reported above (Table I and Fig. 1) and the UL99 gene of the HCMV Towne strain (GenBank accession no: FJ616285.1). A probe located from nt 27537 to 27323 complementary to the antisense strand of the UL21.5 gene locus was synthesized. The separated RNA was transferred onto a positively charged nylon membrane by capillary transfer. Subsequently, the nylon membrane was baked at $80^{\circ} \mathrm{C}$ for $2 \mathrm{~h}$ followed by pre-hybridization at $65^{\circ} \mathrm{C}$ for $30 \mathrm{~min}$ using DIG Easy Hyb buffer and hybridization to the UL21.5 and UL99 probes at $65^{\circ} \mathrm{C}$ for $16 \mathrm{~h}$. The hybridized probes were reacted to the anti-DIG conjugated to alkaline phosphatase and the chemiluminescence substrate CDP-Star, and were exposed using ChemiDoc ${ }^{\mathrm{TM}} \mathrm{XRS}+$ (Bio-Rad Laboratories, Hercules, CA, USA). To ensure that equal amounts of RNA were loaded in each experiment, the RNA preparations were adjusted by comparing them to the quantities of the 28S and 18S rRNA in the same RNA preparations, which were estimated by electrophoresis and ethidium bromide staining.

Reverse transcription PCR (RT-PCR). According to the results of cDNA library screening, a set of primers, flanking the introns of the spliced transcripts identified, were designed. RT-PCR was performed using an RNA PCR kit (AMV) version 3.0 (Takara Biotechnology, Dalian, China). First-strand cDNA was synthesized with an oligo(dT) primer at $42^{\circ} \mathrm{C}$ for $30 \mathrm{~min}, 95^{\circ} \mathrm{C}$ for $5 \mathrm{~min}$, $5^{\circ} \mathrm{C}$ for 5 min using L RNA from the HCMV H-infected MRC-5 cells. Subsequently, hot-start nested PCR was performed using two pairs of primers, R-s1 and R-a1, as well as R-s2 and R-a2 for identification of the spliced transcripts, and using primers R-s3 and $5^{\prime} \mathrm{R} 3$, as well as R-s3 and $5^{\prime} \mathrm{R} 4$ for the identification of the UL21.5 transcripts (Table I and Fig. 1). All the reactions were carried out at $94^{\circ} \mathrm{C}$ for $3 \mathrm{~min}, 30$ cycles of $94^{\circ} \mathrm{C}$ for $30 \mathrm{sec}, 56^{\circ} \mathrm{C}$ for $30 \mathrm{sec}$, and $72^{\circ} \mathrm{C}$ for $2 \mathrm{~min}$, and a final extension at $72^{\circ} \mathrm{C}$ for $10 \mathrm{~min}$. A negative control reaction by omitting the reverse transcription step was carried out concurrently.

Rapid amplification of cDNA ends (RACE). To determine the $3^{\prime}$ and $5^{\prime}$ ends of the UL21.5 transcripts, RACE was performed using the 3'-full RACE Core Set version 2.0 and 5'-full RACE kits (Takara Biotechnology) according to the manufacturer's instructions. Using L RNA preparations from the HCMV H-infected MRC5 cells, first-strand cDNA was synthesized with M-MLV reverse transcriptase using oligo(dT)-adaptor primer (3'RACE) and random 9-mer Primer (5'RACE) provided by the respective kits. In the 5'RACE experiments, reactions without tobacco acid pyrophosphatase (TAP) and M-MLV, which exclude the interference caused by the 5 -terminal phosphate of tRNA, rRNA and incomplete mRNA and exclude the interference caused by DNA pollution, were performed as two control reactions. Subsequently, specific sequences of the first-strand cDNA were amplified by PCR using the specific primers, $3^{\prime} \mathrm{F} 1$ and $3^{\prime} \mathrm{F} 2$ for $3^{\prime} \mathrm{RACE}$, and the primers, $5^{\prime} \mathrm{R} 1$ and $5^{\prime} \mathrm{R} 2$, as well as $5^{\prime} \mathrm{R} 3$ and $5^{\prime} \mathrm{R} 4$, for $5^{\prime} \mathrm{RACE}$. The primers are listed in Table I and shown in Fig. 1. 
Table I. Primers used in the study.

\begin{tabular}{|c|c|c|c|}
\hline Experiment & Primer name & Sequence $\left(5^{\prime} \rightarrow 3^{\prime}\right)$ & Position $\left(5^{\prime} \rightarrow 3^{\prime}\right)$ \\
\hline \multirow{7}{*}{$\begin{array}{l}\text { cDNA library } \\
\text { screening and } \\
\text { RACE }\end{array}$} & R-s3 & GGCTTTGGCGGCACCTTCT & $27116-27134$ \\
\hline & $3^{\prime} \mathrm{F} 1$ & GGCAACATCTCTTCATCTCCC & $26601-26621$ \\
\hline & 3'F2 & GCGTAGAAAGCCAAGCGG & $26691-26708$ \\
\hline & 5 'R1 & CCGTTAGGTTAGTCACGCTCCA & $25515-25494$ \\
\hline & 5'R2 & AGTCACGCTCCAACTACCCTCA & $25505-25484$ \\
\hline & 5'R3 & GTCGGTCTTCTCTTGTGG & $27421-27404$ \\
\hline & $5 ' \mathrm{R} 4$ & CCATCTCCGTCTGTAATCAAAA & $27387-27366$ \\
\hline \multirow{6}{*}{$\begin{array}{l}\text { Northern } \\
\text { blot analysis }\end{array}$} & 21.5-NS1 & CAGGGCTACCTCCCATCGC & $26785-26803$ \\
\hline & 21.5-NAS1 & TGCTGAGGTCTTGTCGGCG & $27069-27051$ \\
\hline & $21.5-\mathrm{NS} 2$ & ACCACCGACGGAAACGAAGAT & $27323-27343$ \\
\hline & 21.5-NAS2 & GAGCAGAACCTTACAGCTTTTTA & $27537-27515$ \\
\hline & 99-NS & CTGGGCTGCGAGTTGCTGGC & $144702-144721$ \\
\hline & 99-NAS & GATGGTGGTGATGTTTTGAGGGTT & $145235-145212$ \\
\hline \multirow[t]{7}{*}{ RT-PCR } & R-s1 & CGGGCTATGCTGGTGATG & $25269-25286$ \\
\hline & R-a1 & CGCCGCTTGGCTTTCTAC & $26710-26693$ \\
\hline & R-s2 & GATGCTGGATTACTACTGGA & $25283-25302$ \\
\hline & $\mathrm{R}-\mathrm{a} 2$ & AGCTCGTCGGAGGCTTTT & $26684-26667$ \\
\hline & R-s3 & GGCTTTGGCGGCACCTTCT & $27116-27134$ \\
\hline & $5 ' \mathrm{R} 3$ & GTCGGTCTTCTCTTGTGG & $27421-27404$ \\
\hline & 5'R4 & СCATCTCCGTCTGTAATCAAAA & $27387-27366$ \\
\hline \multirow{12}{*}{$\begin{array}{l}\text { Plasmid } \\
\text { construction }\end{array}$} & M-S & acgcGTCGACTGCTGGTGATGCTGGATTACTACT & $25276-25299$ \\
\hline & M-AS & aaggaaaaaaGCGGCCGCGTCGGTCTTCTCTTGTGGTT & $27421-27402$ \\
\hline & M-d-as & ggaAGATCTTGAGGGTTGGGTTGATGCAACTCTCCGTTAGG & $25530-25508$ \\
\hline & M-dL-s & ggaAGATCT CCTATATAACTACCATCTGGCTTCTG & $25540-25565$ \\
\hline & M-a1-as & ggaAGATCTGATGTTTTGAGGGTTGCGTCATCGACCGACCTCCGC & $26576-26557$ \\
\hline & M-a1L-s & ggaAGATCTATCCGGCAACATCTCTTCATCTCCC & $26597-26621$ \\
\hline & M-a2-a1 & ggaAGATCTGATGTTTTGAGGGTTGGAGATGTTGCCGGATCTGCCG & $26612-26591$ \\
\hline & M-a2L-s1 & ggaAGATCT CACACGGCGCTGTTCTGGATGTAT & $26633-26656$ \\
\hline & M-a2-a2 & $\begin{array}{l}\text { ggaAGATCTGATGTTTTGAGGGTTGGGAGAC } \\
\text { GAAGAGATGTTACCGGATC }\end{array}$ & $26620-26596$ \\
\hline & M-a2L-s2 & ggaAGATCT GCTGTTCTGGATGTATATGATTC & $26641-26663$ \\
\hline & M-a2-a3 & $\begin{array}{l}\text { ggaAGATCTGGATGGTGGTGATGTTTTGAGGGTT } \\
\text { GGAGACGAAGAGATGTTACCGGA }\end{array}$ & $26620-26598$ \\
\hline & M-a2L-s3 & ggaAGATCTATGTATATGATTCTGGAAAAGCCTC & $26651-26675$ \\
\hline
\end{tabular}

Normal fonts represent gene-specific sequences, italic fonts represent mutant sequences. Sequences underlined are recognition sites of the restriction enzymes, SalI (GTCGAC), NotI (GCGGCCGC) and BgIII (AGATCT). Sequence positions shown refer to those of the Towne strain (GenBank accession no: FJ616285.1).

Plasmid construction. To construct an expression vector for the UL21.5 gene, the sequence containing all the introns of the HCMV UL21.5 gene region from nt 25276 to 27421 was amplified by PCR using $\mathrm{H}$ strain DNA as a template and a pair of primers, M-S and M-AS, which introduce a SalI and Not I recognition site into the ends of the amplicon respectively (Table I). The PCR products were digested using SalI and NotI, and then cloned into the SalI and NotI sites of the pCMV-HA vector, resulting in the plasmid, pCMVUL21.5 MST (Table II).
To identify the determinant regulatory region of the splice sites found in this study, recombinant vectors carrying mutant sequences adjacent to one splice donor site (D1 at nt 25533) and two splice acceptor sites (A1 at nt 26597 and A2 at nt 26633) were generated using specific primers containing mutant sequences.

To generate an expression vector with a mutant sequence around the splice donor site D1, a 9-bp sequence from nt 25531 to nt 25539 was mutated from GCGGTGAGT to TGAGGGTTG. First, one 264-bp SalI-BglII fragment and one 1882-bp BglIINotI fragment were amplified using two pairs of primers, M-S 


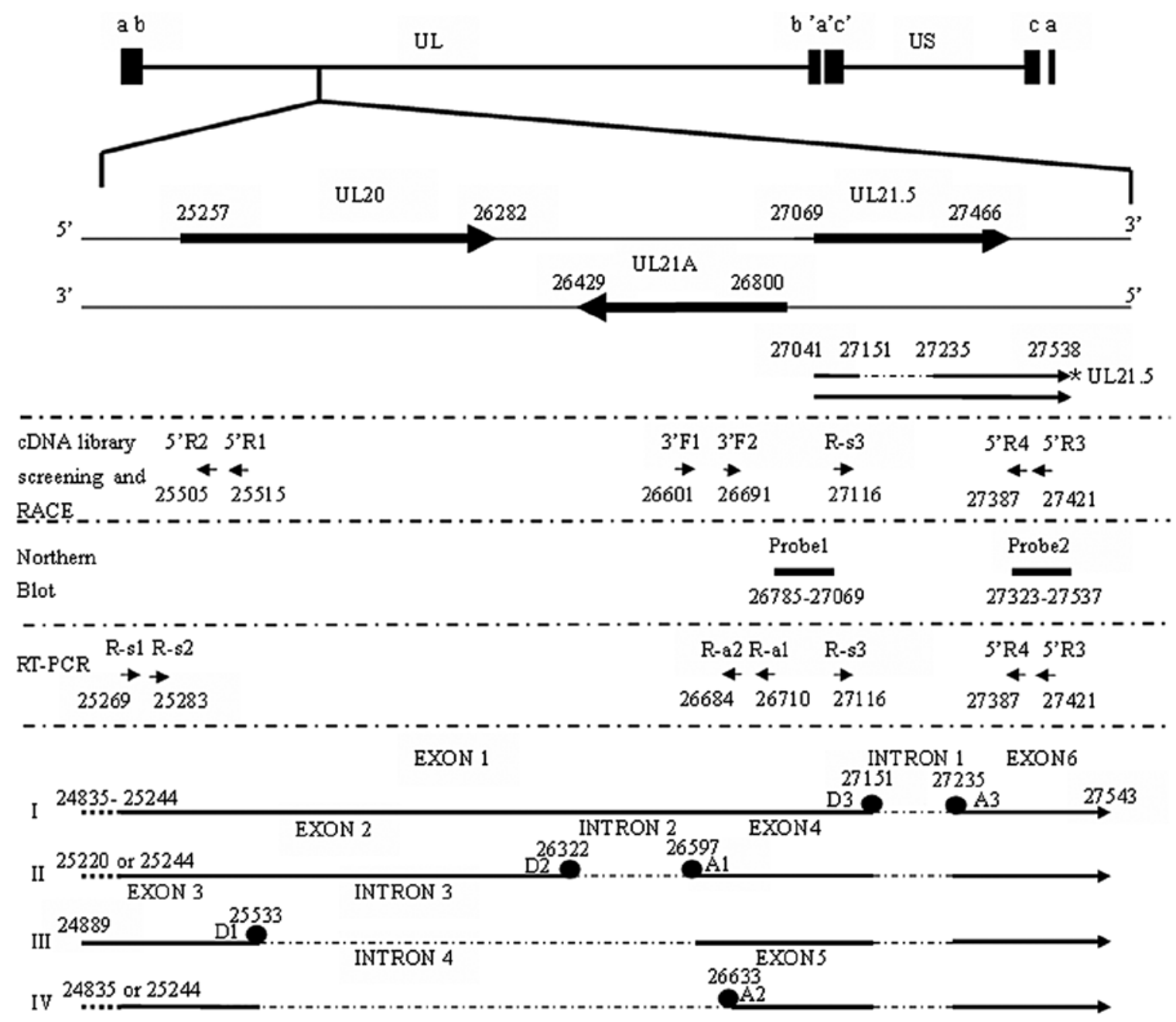

Figure 1. The location of the HCMV UL20-UL21.5 gene region in the genome and structures of HCMV UL21.5 MST identified in the present study. The upper two strands represent the genome of Towne strain (GenBank accession no: FJ616285.1). The thick arrows represents the UL20, UL21A or UL21.5 genes. The start and stop sites of each gene are marked. The bottom solid lines represent exon structures, while the dotted lines represent intron structures. "UL21.5 shows two transcripts reported by Rawlinson and Barrell (18), which are located in the complementary strand of the UL21A gene (5). The specific probe for the detection of multiple spliced transcripts of UL21.5 by northern blot analysis, primers for RT-PCR and nested RACE PCR are indicated by black bars and arrows, respectively. The positions of probes and the $5^{\prime}$ ends of the primers are marked according to those of HCMV Towne strain. The dotted lines indicate the possible 5 ' ends located from nt 24835 to nt 25244 . Four spliced transcripts found in this study are labeled with I, II, III and IV. Dark spots represent the splice donor sites (D1, D2 and D3) and splice acceptor sites (A1, A2 and A3).

and M-d-as, as well as M-dL-s and M-AS. Following digestion with SalI and BglII, as well as BglII and NotI, the fragments were inserted into the pCMV-HA vector at the SalI and NotI sites, resulting in pCMV-UL21.5-mut-D1 (Table II).

To construct an expression vector with a mutant sequence adjacent to the splice acceptor site A1 at nt 26597, a 20-bp sequence located upstream of the A1 site from nt 26577 to nt 6596 was mutated from GGATTGGGTAGGGGTTGCAG to GATCTGATGTTTTGAGGGTT. Using two pairs of primers, M-S and M-a1-as, as well as M-a1L-s and M-AS, one 1,321-bp SalI-BglII fragment and one 825-bp BglII-NotI fragment were obtained. Following digestion with SalI and $B g l \mathrm{II}$, as well as $B g l \mathrm{II}$ and $N o t \mathrm{I}$, the fragments were cloned into the SalI and NotI sites of the pCMV-HA vector, resulting in pCMV-UL21.5-mut-A1 (Table II).

To generate an expression vector containing a mutant sequence around the splice acceptor site A2 at nt 26633, a series of expression vectors, pCMV-UL21.5-mut-A2-1 containing a 20-bp mutant sequence located upstream of the A2 site from nt 26613 to nt 26632, pCMV-UL21.5-mut-A2-2 containing a 20-bp mutant sequence around the A2 site from nt 26621 to nt 26640 and pCMV-UL21.5-mut-A2-3 containing a mutant sequence from nt 26621 to nt 26650 were generated using a method similar to the one described above. In pCMV-UL21.5mut-A2-3, a 30-bp sequence adjacent to the splice acceptor site A2 was mutated from CTCACCGACCAGCACACGG CGCTGTTCTGG to GATCTGGATGGTGGTGATGTTTT GAGGGTT (Table II). The inserts of the plasmids constructed above were confirmed by sequencing.

Transfection of HEK 293 cells and detection of transcripts by $R T$-PCR. The HEK 293 cells were plated onto 6-well plates at a density of $2 \times 10^{5}$ cells/well. Twenty-four hours later, the cells were transfected with $4 \mu \mathrm{g}$ of each plasmid DNA (pCMV-UL21.5 MST, pCMV-UL21.5-mut-D1, pCMV-UL21.5-mut-A1, pCMV-UL21.5-mut-A2-1, pCMV-UL21.5-mut-A2-2 and pCMV-UL21.5-mut-A2-3) using $10 \mu 1$ Lipofectamine 2000 (Invitrogen, Carlsbad, CA, USA) diluted in serum-free medium 
Table II. Results identified by the in vitro expression system.

\begin{tabular}{|c|c|c|c|c|c|}
\hline Plasmids & $\begin{array}{l}\text { Mutation } \\
\text { regions }\end{array}$ & $\begin{array}{c}\text { Original } \\
\text { sequences }\end{array}$ & $\begin{array}{l}\text { Mutation } \\
\text { sequences }\end{array}$ & $\begin{array}{c}\text { Detected } \\
\text { transcripts }\end{array}$ & $\begin{array}{l}\text { Undetected } \\
\text { transcripts }^{\mathrm{a}}\end{array}$ \\
\hline $\begin{array}{l}\text { pCMV- } \\
\text { UL21.5 MST }\end{array}$ & & & & I, II, III, IV & No \\
\hline $\begin{array}{l}\text { pCMV-UL21.5 } \\
\text {-mut-D1 }\end{array}$ & $\begin{array}{l}\mathrm{D} 1(\mathrm{nt} 25533) / \\
\mathrm{nt} 25531-39^{\mathrm{b}}\end{array}$ & GCGGTGAGT & TGAGGGTTG & $\mathrm{I}, \mathrm{II}$ & III, IV \\
\hline $\begin{array}{l}\text { pCMV-UL21.5 } \\
\text {-mut-A1 }\end{array}$ & $\begin{array}{l}\text { A1(nt26597)/ } \\
\text { nt26577-96 }\end{array}$ & $\begin{array}{l}\text { GGATTGGGTA } \\
\text { GGGGTTGCAG }\end{array}$ & $\begin{array}{l}\text { GATCTGATGT } \\
\text { TTTGAGGGTT }\end{array}$ & I, IV & II, III \\
\hline $\begin{array}{l}\text { pCMV-UL21.5 } \\
\text {-mut-A2-1 }\end{array}$ & $\begin{array}{c}\mathrm{A} 2(\mathrm{nt} 26633) / \\
\mathrm{nt} 26613-32\end{array}$ & $\begin{array}{l}\text { TCGTCTCCCT } \\
\text { CACCGACCAG }\end{array}$ & $\begin{array}{l}\text { GATCTGATGT } \\
\text { TTTGAGGGTT }\end{array}$ & I, II, III, IV & No \\
\hline $\begin{array}{l}\text { pCMV-UL21.5 } \\
\text {-mut-A2-2 }\end{array}$ & $\begin{array}{l}\text { A2(nt26633)/ } \\
\text { nt26621-40 }\end{array}$ & $\begin{array}{l}\text { CTCACCGACC } \\
\text { AGCACACGGC }\end{array}$ & $\begin{array}{l}\text { GATCTGATGT } \\
\text { TTTGAGGGTT }\end{array}$ & I, II, III, IV & No \\
\hline $\begin{array}{l}\text { pCMV-UL21.5 } \\
\text {-mut-A2-3 }\end{array}$ & $\begin{array}{c}\mathrm{A} 2(\mathrm{nt} 26633) / \\
\mathrm{nt} 26621-50\end{array}$ & $\begin{array}{l}\text { CTCACCGACC } \\
\text { AGCACACGGC } \\
\text { GCTGTTCTGG }\end{array}$ & $\begin{array}{l}\text { GATCTGGATG } \\
\text { GTGGTGATGT } \\
\text { TTTGAGGGTT }\end{array}$ & I, II, III & IV \\
\hline
\end{tabular}

${ }^{\text {aS }}$ Spliced transcripts undetected in the in vitro expression system by the primers, R-s2 and R-a2. ${ }^{b}$ Positions of the splice donor and acceptor sites. Transcripts II and III are related to acceptor site A1, transcript IV is related to acceptor site A2, and transcripts III and IV are related to donor site D1.

as recommended by the manufacturer. The cells were harvested $48 \mathrm{~h}$ after transfection, and the RNA of the transfected cells was prepared as described above. Subsequently, RT-PCR was performed using the RNA preparations and one pair of primers, R-s2 and R-a2. The total RNA isolated from the HEK 293 cells and the pCMV-HA-transfected HEK 293 cells was used as the controls. An RT-PCR reaction without M-MLV in the reverse transcription step was performed concurrently.

Cloning and sequencing. All the RACE and RT-PCR products were gel-purified and cloned into the vector, PCR2.1 (Invitrogen). Subsequently, the inserts of the identified clones were sequenced on the ABI PRISM 3730 DNA analyzer (Applied Biosystems). The nucleotide positions referred to in the present study are in reference to the sequence of the HCMV Towne strain (GenBank accession no: FJ616285.1).

\section{Results}

UL21.5 spliced transcripts obtained from the cDNA library. By graded PCR screening, $34 \mathrm{cDNA}$ clones were found to contain sequences congruent with the UL21.5 gene locus from 8,600 clones of the HCMV cDNA library. The sequencing results revealed that all $34 \mathrm{cDNA}$ sequences terminated at nt 27543, which is downstream of a poly(A) signal (ATTAAA) at nt 27513-27518. Among the identified cDNA sequences, 25 sequences with lengths from $417 \mathrm{nt}$ to $421 \mathrm{nt}$ began at the region from nt 27040 to nt 27044 , which are similar to the spliced UL21.5 transcript reported previously (18). Five sequences with lengths from $765 \mathrm{nt}$ to $1386 \mathrm{nt}$ began from nt 26696 to 26082 , which have a similar structure as transcript I (Fig. 1). The sequence with its $5^{\prime}$ end at nt 24889 comprised three exons and two introns (Fig. 1, transcript III), and was 1473 nt in length.
However, no clone containing an unspliced UL21.5 sequence or a sequence from the antisense strand of the UL21.5 gene was obtained from the cDNA library.

UL21.5 transcripts identified by northern blot analysis. To analyze potential transcripts arising from the UL21.5 gene locus during HCMV infection, northern blot analyses were performed using RNA preparations from the MRC-5 cells infected with the HCMV $\mathrm{H}$ strain at the IE, E and $\mathrm{L}$ phases and RNA from mock-infected cells. Three clusters of low-abundance transcripts with lengths of $\sim 1250 \mathrm{nt}, \sim 1517 \mathrm{nt}$ and 1900-2100 nt were detected in the L RNA preparation by the UL21.5-specific probe 1, which is located at nt 26785-27069 (Fig. 2, lane 8). A cluster of an abundant transcript $\sim 400-600$ bp was detected in the same L RNA by the UL21.5-specific probe 2, which was located at nt 27323 to 27537 (Fig. 2, lane 12). No specific band to any of the UL21.5 probes was observed in the IE, E or mock-infected RNA preparations (Fig. 2, lanes 5-7 and 9-11). A specific band to the UL99 probe, which is a true late phase gene (23), was detected in the L RNA preparation but not in the IE and E RNA preparations (Fig. 2, lanes 1-4). No transcript was detected by the probe complementary to the antisense strand of the UL21.5 gene locus (data not shown).

UL21.5 multiple spliced transcripts confirmed by RT-PCR analyses. To confirm the UL21.5 spliced transcripts obtained from the cDNA library and identify more spliced transcripts, RT-PCR was performed using L RNA preparations of the HCMV H strain. The sequencing results revealed that, apart from the UL21.5 transcripts (Fig. 3B), four spliced transcripts (Fig. 1, transcripts I to IV) were transcribed from the UL21.5 transcription region (Fig. 3A) mediated by different combinations of three splice donor sites and three splice acceptor sites (Fig. 1 


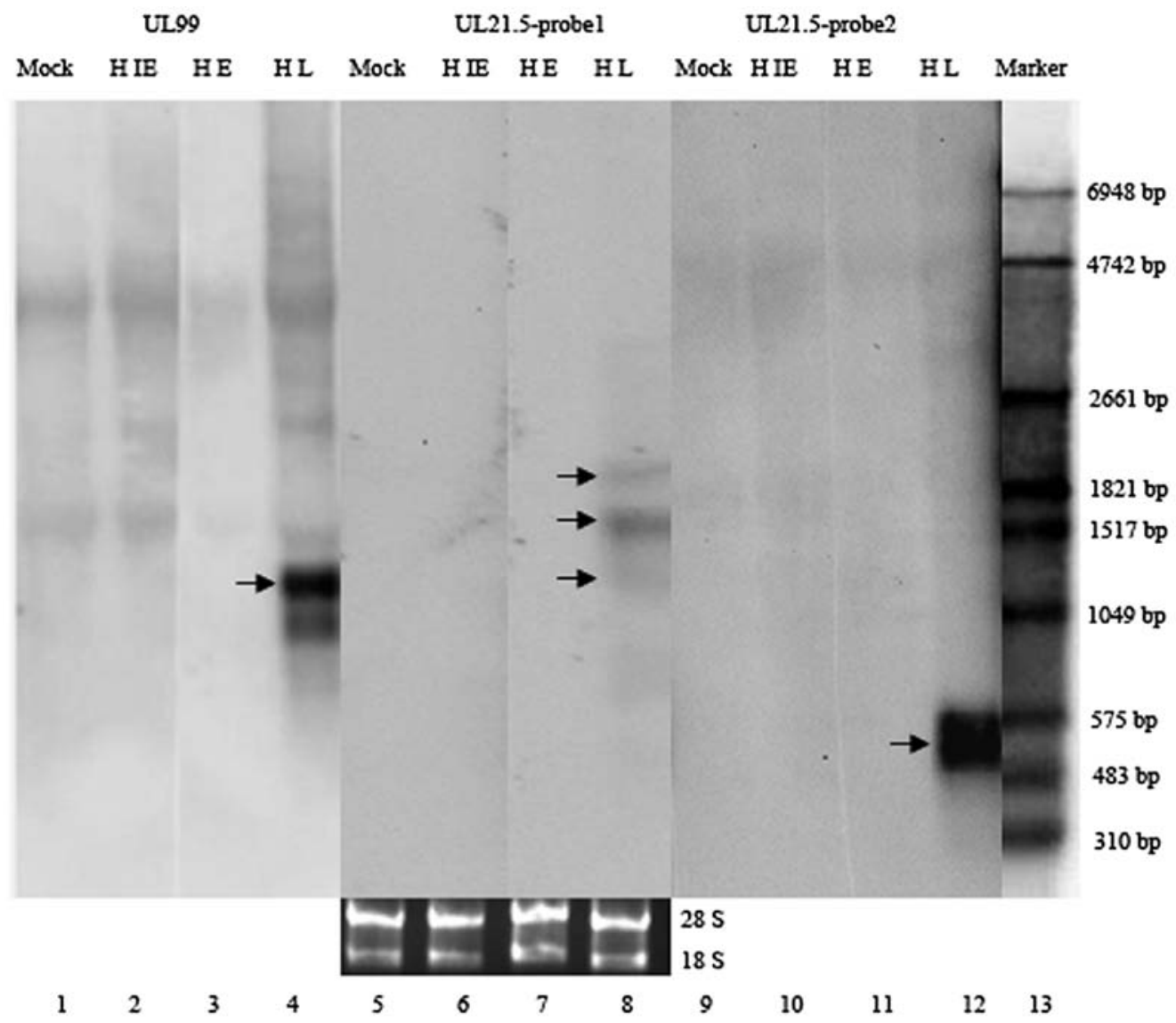

Figure 2. Northern blot analysis of UL21.5 transcripts. Total cellular RNA prepared from uninfected cells (Mock) and HCMV- [at a multiplicity of infection (MOI) of 2] infected cells at the immediate-early (IE), early (E) and late (L) infection phases were examined by northern blot analysis using HCMV UL21.5specific probe 1 (located at nt 26785-27069) and probe 2 (located at nt 27323 to 27537) and UL99-specific probe, respectively. Equivalent amounts of RNA, $10 \mu \mathrm{g}$ in lanes 5-8 and $5 \mu \mathrm{g}$ in lanes 1-4 and 9-12, were subjected to agarose gel electrophoresis in each experiment. Quantities of 28S and 18S rRNA in the RNA preparations were estimated by electrophoresis and ethidium bromide staining. Positions of molecular size markers (03-6.9 kb) are noted at the right side. Black arrows point to the specific bands.

A

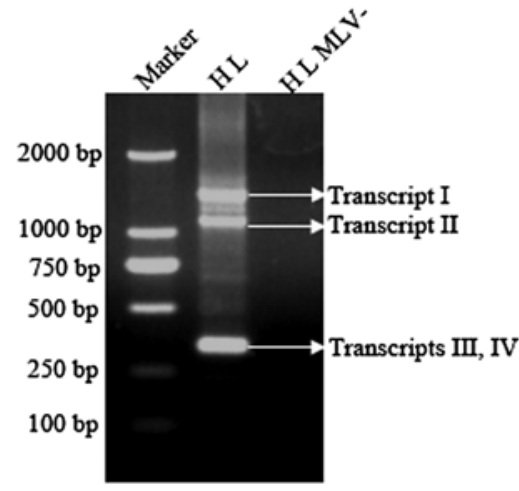

$\mathrm{B}$

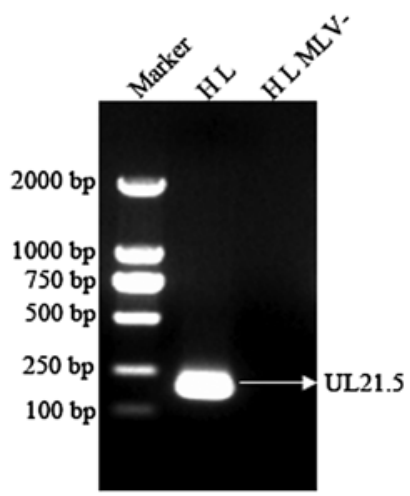

Figure 3. Results of RT-PCR for UL21.5 transcripts. RT-PCR was performed using the late-phase (L) RNA of the H strain (HL) and two pairs of primers, R-s1 and R-a1, as well as R-s2 and R-a2, which were located upstream of the splice donor site D1 at nt 25533 and downstream of the splice acceptor site A2 at nt 26633 (A), and the primers, R-s3 and 5'R3, as well as R-s3 and 5'R4, which span the intron 1 (B). Based on sequencing results, RT-PCR products of the UL21.5 spliced transcripts are indicated by arrows with corresponding names. The products of transcripts I, II, III and IV were amplified by RT-PCR using the primers, R-s1 and R-a1, as well as R-s2 and R-a2 and were 1402,1114, 338 and 302 bp in length, respectively. Those of the UL21.5 transcript were 188 bp (spliced) and 272 bp (unspliced). To exclude the possibility of DNA contamination, a reverse reaction without reverse transcriptase M-MLV (MLV-) was used as a negative control.

and Table III). The UL21.5 gene locus consisted of six exons and four introns (Fig. 1). The largest intron is intron 4, which is located between the splice donor site D1 at nt 25533 and the splice acceptor site A2 at nt 26633, with a length of $1099 \mathrm{nt}$. The shortest intron is intron 1 which is located between the splice donor site D3 at nt 27151 and the splice acceptor site A3 at nt 27235 , with a length of $83 \mathrm{nt}$. Alterable combinations of the six exons constitute the four spliced transcripts (Fig. 1).

$3^{\prime}$ and 5' ends of UL21.5 multiple spliced transcripts mapped by RACE. To further map the $3^{\prime}$ and $5^{\prime}$ ends of the UL21.5 multiple spliced transcripts (UL21.5MST), RACE experi- 
Table III. Splicing patterns of UL21.5 MST mapped in the study.

\begin{tabular}{|c|c|c|c|c|c|c|c|}
\hline \multirow[b]{2}{*}{ Intron name } & \multicolumn{3}{|c|}{ Related donor } & \multicolumn{3}{|r|}{ Related acceptor } & \multirow[b]{2}{*}{ Splicing pattern } \\
\hline & Name & Position & Sequence & Name & Position & Sequence & \\
\hline Int 1 & D3 & 27151 & CAGIGTAAAAC & A3 & 27235 & CGCGGTTATCGTTTTTGCAG|C & GT-AG \\
\hline Int 2 & D2 & 26309 & $\mathrm{GCG} \mid \underline{G T A C G G}$ & A1 & 26597 & 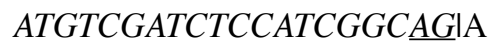 & GT-AG \\
\hline Int 3 & D1 & 25533 & $\mathrm{GCG} \mid \underline{G T G A G T}$ & A1 & 26597 & ATGTCGATCTCCATCGGC $\underline{A G \mid \mathrm{A}}$ & GT-AG \\
\hline Int 4 & D1 & 25533 & GCGIGTGAGT & A2 & 26633 & ТС GТСТСССТСАСС & GT-AG \\
\hline
\end{tabular}

A1-A3 and D1-D3 represent the names of splice acceptor and donor sites, respectively. Normal fonts represent exon sequences, and italic fonts represent the intron sequences. The positions of the donor and acceptor sites refer to the sequence of the Towne strain (GenBank accession no: FJ616285.1). Nucleotides for the formation of the splicing patterns are underlined.

A

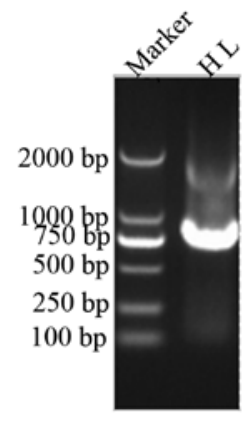

B

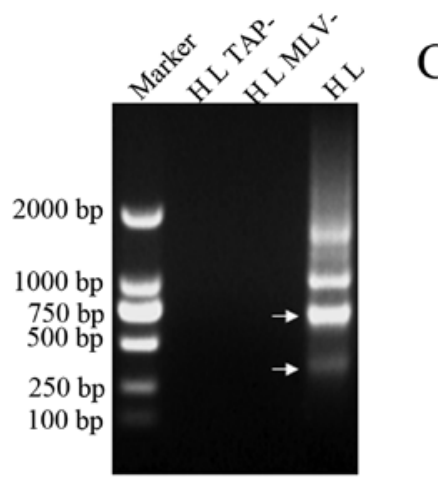

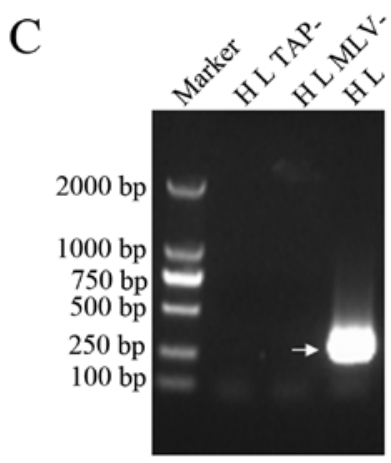

Figure 4. RACE results of the UL21.5 transcripts. Late-phase (L) RNA preparations from HCMV H-infected MRC5 cells (HL) were used as a template (A) Results of 3'RACE using the gene-specific primers, 3'F1 and 3'F2. (B and C) Results of 5'RACE using two pairs of specific primers, 5'R1 and 5'R2, as well as 5'R3 and 5'R4. TAP (-) and MLV (-) are negative controls, in which either TAP or MLV were omitted. The gene-specific bands are marked by white arrows.

ments were performed using the L RNA of the HCMV H strain. The sequencing result of the 3'RACE product (Fig. 4A) identified a $3^{\prime}$ end at nt 27543 downstream of the poly(A) signal (ATTAAA) at nt 27513-27518, which is consistent with that of the transcripts identified by cDNA library screening.

In 5'RACE experiments, two specific products were obtained using 5'R1 and 5'R2 (nested) primers (Table I and Fig. 4B). The sequencing results revealed four possible $5^{\prime}$ ends located at nt 24835, nt 24895, nt 25220 and nt 25244. Based on the structures of transcripts identified by RT-PCR and the overlapping sequences, 16 possible transcript sequences were obtained by linking the sequences obtained from 5' and 3'RACE, as well as sequences obtained by RT-PCR (Table IV). Among these, the transcript lengths with the possible 5' ends at nt 24835 and nt 24895, and the possible structures of transcripts III and IV were 1470-1566 nt, which may correspond to the $\sim 1517 \mathrm{nt}$ transcripts found in northern blot analysis. By contrast, the lengths of transcripts with the possible 5' ends at nt 25220 and nt 25244 and the possible structures of transcripts III and IV were 1121$1179 \mathrm{nt}$, which may correspond to the $\sim 1250 \mathrm{nt}$ transcripts, and those with the possible 5' ends at nt 25220 and nt 25244, and the possible structures of transcript II were 1946-1968 nt, which may correspond to the 1900-2100 nt transcripts identified in northern blot analysis. Four ORFs were predicted in the spliced transcripts identified (Table IV). As the ORF predicted in the UL21.5 spliced transcript, ORF A (from nt 27069 to nt 27151 and from nt 27235 to nt 27466), ORF B (from nt 26845 to nt 27093) and ORF C (from nt 26651 to nt 26929) were exactly the same in transcripts II, III and IV. And ORF D, E and F were specific for transcripts II, III and IV, respectively.

In order to confirm the 5' ends located from nt 27040 to 27044, which were obtained in the cDNA library screening, two other nested primers, 5'R3 and 5'R4 (Table I and Fig. 1), were used in 5'RACE. One 300-bp product was obtained (Fig. 4C). The sequencing results of this product showed three possible 5' ends located at nt 27040, 27041 and 27043, respectively; this was in accordance with the results of cDNA library screening.

Determinant regulatory region for a splice donor site and two splice acceptor sites identified by an in vitro expression system. To confirm that the UL21.5 MST was derived from splice events, the plasmid, pCMV-UL21.5 MST, was constructed. As shown in lane 8 of Fig. 5, in accordance with those identified by RT-PCR using the primers, R-s2 and R-a2, four spliced transcripts were confirmed by the sequencing results of the bands.

To identify the determinant regulatory regions necessary for splice sites D1 (at nt 25533), A1 (at nt 26597) and A2 (at nt 26633) (Fig. 1) in the UL21.5 gene locus, expression vectors containing mutant sequences around the splice donor site D1 and adjacent to the splice acceptor sites A1 and A2 were constructed (Table II). RT-PCR analyses were performed using RNA preparations from the HEK 293 cells trans- 
Table IV. Analyses of the UL21.5 multiple spliced transcripts based on RACE.

Transcripts with possible

5 ' ends and structures

\begin{tabular}{|c|c|c|c|c|}
\hline Structure & 5 ' ends & Length (nt) & $\begin{array}{l}\text { Correspond to transcripts } \\
\text { found in northern blot analysis }\end{array}$ & $\begin{array}{l}\text { Positions of the predictec } \\
\text { ORFs of the transcripts }\end{array}$ \\
\hline \multirow[t]{4}{*}{ I } & nt 24835 & 2629 & --- & \\
\hline & nt 24895 & 2569 & --- & \\
\hline & nt 25220 & 2242 & --- & \\
\hline & nt 25244 & 2217 & --- & \\
\hline \multirow[t]{4}{*}{ II } & nt 24835 & 2355 & --- & \\
\hline & nt 24895 & 2295 & --- & \\
\hline & nt 25220 & 1968 & $1900-2100 \mathrm{nt}$ & A, B, C and D \\
\hline & nt 25244 & 1946 & $1900-2100 \mathrm{nt}$ & $\mathrm{A}, \mathrm{B}, \mathrm{C}$ and $\mathrm{D}$ \\
\hline \multirow[t]{4}{*}{ III } & nt 24835 & 1566 & $\sim 1517 \mathrm{nt}$ & $\mathrm{A}, \mathrm{B}, \mathrm{C}$ and $\mathrm{E}$ \\
\hline & nt 24895 & 1506 & $\sim 1517 \mathrm{nt}$ & $\mathrm{A}, \mathrm{B}, \mathrm{C}$ and $\mathrm{E}$ \\
\hline & nt 25220 & 1179 & $\sim 1250 \mathrm{nt}$ & $\mathrm{A}, \mathrm{B}, \mathrm{C}$ and $\mathrm{E}$ \\
\hline & nt 25244 & 1157 & $\sim 1250 \mathrm{nt}$ & $\mathrm{A}, \mathrm{B}, \mathrm{C}$ and $\mathrm{E}$ \\
\hline \multirow[t]{4}{*}{ IV } & nt 24835 & 1530 & $\sim 1517 \mathrm{nt}$ & $\mathrm{A}, \mathrm{B}, \mathrm{C}$ and $\mathrm{F}$ \\
\hline & nt 24895 & 1470 & $\sim 1517 \mathrm{nt}$ & $\mathrm{A}, \mathrm{B}, \mathrm{C}$ and $\mathrm{F}$ \\
\hline & nt 25220 & 1143 & $\sim 1250 \mathrm{nt}$ & $\mathrm{A}, \mathrm{B}, \mathrm{C}$ and $\mathrm{F}$ \\
\hline & nt 25244 & 1121 & $\sim 1250 \mathrm{nt}$ & $\mathrm{A}, \mathrm{B}, \mathrm{C}$ and $\mathrm{F}$ \\
\hline
\end{tabular}

According to the possible 5' ends obtained by 5'RACE and structures demonstrated by RT-PCR, possible transcripts were analyzed by comparing them to the transcripts indentified in northern blot analysis. Open reading frames (ORFs) of the identified transcripts were predicted. The positions shown refer to the sequence of the Towne strain (GenBank accession no: FJ616285.1). '--- 'indicates no matched transcript was found in northern blot analysis. ORF A was located from nt 27069 to nt 27151 and from nt 27235 to nt 27466; ORF B was located from nt 26845 to nt 27093; ORF C was located from nt 26651 to nt 26929; ORF D was located from nt25257 to nt 26282; ORF E was located from nt 25257 to nt 25533 and from nt 26597 to nt 26754; ORF F was located from nt 25257 to nt 25533 and from nt 26633 to nt 26754.

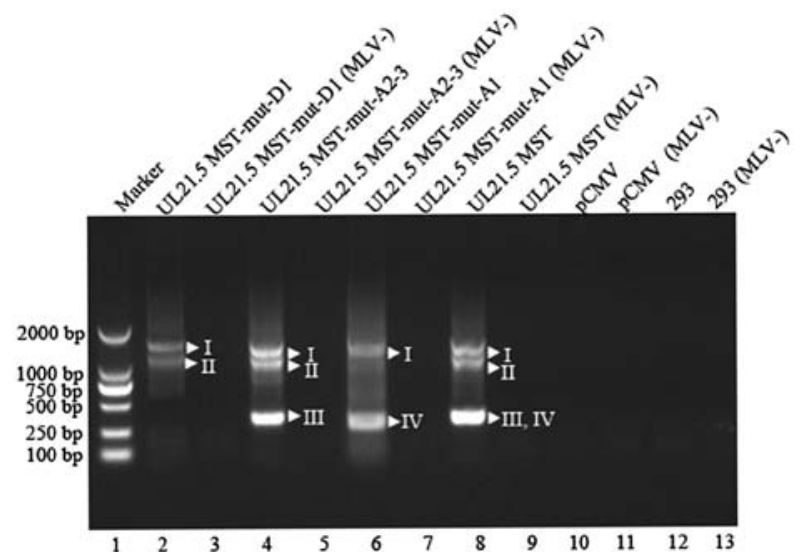

Figure 5. Electrophoresis gel analysis of RT-PCR amplification products from total RNA from HEK 293 cells transfected with the indicated recombinant plasmids. Lanes 3, 5, 7, 9,11 and 13 are negative controls without the addition of reverse transcriptase MLV during the reverse transcription step [MLV(-)]. The products corresponding to the transcripts shown in Fig. 1 are marked by each transcript's name. RT-PCR analyses followed by sequencing were performed on first-strand cDNA using the primers, R-s2 and R-a2. The products of transcripts I, II, III and IV were 1402, 1114, 338 and 302 bp in this amplification system.

fected with pCMV-UL21.5-mut-D1, pCMV-UL21.5-mut-A1, pCMV-UL21.5-mut-A2-1, pCMV-UL21.5-mut-A2-2 and pCMV-UL21.5-mut-A2-3, and one pair of primers, R-s2 and
$\mathrm{R}-\mathrm{a} 3$. The sequencing results of the RT-PCR products revealed that transcripts III and IV, which are relevant to the splice donor site D1, were not obtained from the HEK 293 cells transfected with pCMV-UL21.5-mut-D1 (Fig. 5, lane 2 and Table II) due to a 9-bp sequence mutation from nt 25531 to nt 25539 around the splice donor site D1. However, transcripts II and III, which are relevant to the splice site A1, were not detected in the HEK 293 cells transfected with pCMV-UL21.5-mut-A1 (Fig. 5, lane 6 and Table II) for a 20-bp sequence mutation from nt 26577 to nt 26596 just upstream the splice acceptor site A1. The structures of UL21.5 MST from the HEK 293 cells transfected with pCMV-UL21.5-mut-A2-1 and pCMV-UL21.5-mut-A2-2 were the same as those from the HEK 293 cells transfected with pCMV-UL21.5 MST (data not shown). Only transcripts from the HEK 293 cells transfected with pCMV-UL21.5-mut-A2-3, which contains a mutant sequence from nt 26621 to nt 26650 , showed the loss of transcript IV (Fig. 5, lane 4 and Table II), which is relevant to the splice acceptor site A2, due to a further 10-bp fragment mutation of GCTGTTCTGG from nt 26641 to 26650, compared to the pCMV-UL21.5-mut-A2-2.

\section{Discussion}

It has been previously believed that HCMV mRNA splicing is restricted to a relatively small IE region of the HCMV genome (24), until a group of spliced L genes were 
described (18). The UL21.5 transcript, which consists of a spliced and a non-spliced transcript, was first reported by Rawlinson and Barrell (18) and later re-termed by Bresnahan and Shenk (17). The UL21.5 transcript is an important HCMV virion RNA for the virus replication cycle (25). Together with the HCMV virion, the UL21.5 transcript is delivered into the infected cell and is translated to a secreted glycoprotein, which functions as a viral chemokine decoy receptor specifically interacting with the RANTES chemokine $(17,19)$. It is also possible that virion-RNA plays a structural role in the HCMV assembly.

In the present study, transcripts from the HCMV UL21.5 region were further analyzed using a low passage HCMV strain. Apart from the higher abundant UL21.5 transcripts reported, three clusters of low-abundance transcripts were detected by probe 1 in L RNAs in northern blot experiments. Four spliced transcripts with a 3 ' co-terminus at nt 27543 of the UL21.5 gene locus were identified by cDNA library screening, RACE and RT-PCR. One ORF, which was the same as that predicted in the UL21.5 spliced transcript, was predicted in all possible forms of the low-abundance spliced transcripts II, III and IV. Apart from this ORF, three transcript-specific ORFs were predicted in the low-abundance spliced transcripts II, III and IV, respectively (Table IV).

In general, three classes of transcripts are expressed from a genome, including high-, intermediate- and low-abundance transcripts (26). Although the majority of the high- and intermediate-abundance transcripts have been identified, it remains a serious challenge to identify the low-abundance transcripts $(27,28)$. To date, some low-abundance transcripts have been identified in HCMV. As a low-abundance spliced transcript from the IE gene region, the IE18 transcript was previously detected in infected human monocyte-derived macrophages at the IE phase, but was not detectable during normal infection (29). The authors concluded that the IE18 transcript exhibits cell type-specific expression indicating differential regulation of the major IE gene region in different permissive cell types (29). By detection in peripheral blood mononuclear cells of organ transplant recipients with different viral DNA loads, the natural killer (NK) cell decoy gene, UL18, was demonstrated to be produced through a low-abundance transcript late during the infectious cycle at a time coincidental with the increased risk of NK cell lysis (30). It can be hypothesized that the existence of the lowabundance UL21.5 spliced transcripts in the HCMV genome may also play some unknown role during HCMV infection.

Little was known about splicing situations in HCMV until deep sequencing was used to bring high resolution to the HCMV transcriptome (16). Multiple spliced transcripts have been found in UL37, UL73, UL111A, UL122, UL123, UL128 and US3 to date $(14,15,29,31-39)$. In the present study, four previously unrecognized spliced transcripts were identified. Based on the structures of UL21.5 MST identified in this study and the findings of Rawlinson and Barrell (18), three splice donor sites and three splice acceptor sites were proposed in the UL21.5 gene locus. According to the structures of the four introns indentified in UL21.5 MST, the splicing pattern is a canonical pattern of GT-AG.

Three signals are known to direct splicing events, including the $5^{\prime}$ splice site (5'ss) at the 5 ' end of the intron, the polypyrimidine tract/3' splice site (PPT-3'ss) at the 3 ' end of the intron and a branch site (BS) upstream of the PPT-3'ss (40-43). According to previous studies $(40,41)$, the $5^{\prime}$ element generally is located in the position -3 to +6 (the third position upstream the 5 'ss and the sixth position downstream the 5'ss, respectively), and the essential $3^{\prime}$ element is generally located at nt -3 to -12 upstream of the 3'ss (44-45). To further validate these canonical splice sites and find the determinant regulatory region necessary for splicing events, an in vitro system was used in the present study. Based on the above principles, the expression plasmid, pCMVUL21.5 MST, and plasmids containing mutant 5' element or 3' element of the UL21.5 MST coding sequences were constructed and used in this system. Similar to those found in HCMV H-infected MRC5 cells, four spliced transcripts were identified from HEK 293 cells transfected with the plasmid, pCMV-UL21.5 MST. This finding confirmed that the splicing events occurred during transcription. However, when mutation occurred adjacent to the splice donor site D1 at nt 25533 (in plasmid pCMV-UL21.5-mut-D1), D1-related transcripts (transcripts III and IV) of UL21.5 MST were not detected from the transfected cells. This result indicated that the 9-bp sequence around D1 from nt 25531 to nt 25539, which is exactly in the 5 ' element, is necessary for the activity of the splice donor site D1. Similarly, the 20-bp sequence just upstream of the splice site A1 at nt 26597 from nt 26577 to nt 26596, which includes the 3 ' element, is important for splice acceptor site A1, as mutation in this region resulted in the loss of A1-related transcripts (transcripts II and III). However, the determinant regulatory region that is necessary for activity of splice acceptor site A2 at nt 26633 is located not in the 3' element but in the sequence from nt 26641 to nt 26650, as the plasmid containing a mutant sequence in this region (pCMV-UL21.5-mut-A2-3) led to the loss of A2-related transcripts (transcript IV).

Overall, in addition to the UL21.5 transcript, four novel low-abundance 3'-coterminal spliced transcripts were identified to transcribe from the UL21.5 gene locus during late-phase infection. Three splice donor sites and three splice acceptor sites found in this region were validated to be functional splice sites by an in vitro expression system. Determinant regulatory regions of one splice donor site and two splice acceptor sites were identified in corresponding regions by mutation experiments. Alteration of the donor or acceptor splice sites may result in the loss of their related transcripts.

\section{Acknowledgements}

The present study was supported by the National Natural Science Foundation of China (30672248, 30901625, 81171580 and 81171581) and the Specialized Research Fund for the Doctoral Program of Higher Education (20112104110012) and the Outstanding Scientific Fund of Shengjing Hospital.

\section{References}

1. Mocarski E, Shenk T and Pass RF: Cytomegaloviruses. In: Fields Virology. Knipe DM, Howley PM, Griffin DE, Lamb RA, Martin MA, Roizman B and Straus SE (eds). 5th edition. Lippincott-Raven Publishers, Philadelphia, PA, pp2702-2772, 2007.

2. Mocarski ES: Cytomegaloviruses and their replication. In: Fields virology. Fields BN, Knipe DM and Howley PM (eds). Vol. 2. 3rd edition. Lippincott-Raven Publishers, Philadelphia, PA. pp2447-2492, 1996. 
3. Du G, Dutta N, Lashmit P and Stinski MF: Alternative splicing of the human cytomegalovirus major immediate-early genes affects infectious-virus replication and control of cellular cyclin-dependent kinase. J Virol 85: 804-817, 2011.

4. Griffiths PD, Cope AV, Hassan-Walker AF and Emery VC: Diagnostic approaches to cytomegalovirus infection in bone marrow and organ transplantation. Transpl Infect Dis 1: 179-186, 1999.

5. CheeMS,Bankier AT, Beck S, et al: Analysis of the protein-coding content of the sequence of human cytomegalovirus strain AD169. Curr Top Microbiol Immunol 154: 125-169, 1990.

6. Davison AJ, Dolan A, Akter P, et al: The human cytomegalovirus genome revisited: comparison with the chimpanzee cytomegalovirus genome. J Gen Virol 84: 17-28, 2003.

7. Dolan A, Cunningham C, Hector RD, et al: Genetic content of wild-type human cytomegalovirus. J Gen Virol 85: 1301-1312, 2004.

8. Dunn W, Trang P, Zhong Q, Yang E, van Belle C and Liu F: Human cytomegalovirus expresses novel microRNAs during productive viral infection. Cell Microbiol 7: 1684-1695, 2005.

9. Murphy E, Rigoutsos I, Shibuya T and Shenk TE: Reevaluation of human cytomegalovirus coding potential. Proc Natl Acad Sci USA 100: 13585-13590, 2003.

10. Murphy E, Yu D, Grimwood J, et al: Coding potential of laboratory and clinical strains of human cytomegalovirus. Proc Natl Acad Sci USA 100: 14976-14981, 2003.

11. Ma Y, Wang N,Li M, et al: Human CMV transcripts: an overview. Future Microbiol 7: 577-593, 2012.

12. Maniatis T and Reed R: An extensive network of coupling among gene expression machines. Nature 416: 499-506, 2002.

13. Sandri-Goldin RM: Viral regulation of mRNA export. J Virol 78: 4389-4396, 2004.

14. Awasthi S, Isler JA and Alwine JC: Analysis of splice variants of the immediate-early 1 region of human cytomegalovirus. J Virol 78: 8191-8200, 2004

15. Shirakata M, Terauchi M, Ablikim M, et al: Novel immediate-early protein IE19 of human cytomegalovirus activates the origin recognition complex I promoter in a cooperative manner with IE72. J Virol 76: 3158-3167, 2002.

16. Gatherer D, Seirafian S, Cunningham C, et al: High-resolution human cytomegalovirus transcriptome. Proc Natl Acad Sci USA 108: 19755-19760, 2011.

17. Bresnahan WA and Shenk T: A subset of viral transcripts packaged within human cytomegalovirus particles. Science 288 2373-2376, 2000.

18. Rawlinson WD and Barrell BG: Spliced transcripts of human cytomegalovirus. J Virol 67: 5502-5513, 1993.

19. Dai W, Wade B and Thomas S: Human cytomegalovirus encodes a highly specific RANTES decoy receptor. Proc Natl Acad Sci USA 101: 16642-16647, 2004.

20. Ma YP, Ruan Q, Ji YH, et al: Novel transcripts of human cytomegalovirus clinical strain found by cDNA library screening. Genet Mol Res 10: 566-575, 2011.

21. Sun Z, Ren G, Ma Y, et al: Transcription pattern of UL131A-128 mRNA in clinical strains of human cytomegalovirus. J Biosci 35 365-370, 2010.

22. Qi Y, Ma Y, He R, et al: Characterization of 3' termini of human cytomegalovirus UL138-UL145 transcripts in a clinical strain. Microbiol Immunol 55: 95-99, 2011.

23. Adam BL, Jervey TY, Kohler CP, et al: The human cytomegalovirus UL98 gene transcription unit overlaps with the pp28 true late gene (UL99) and encodes a 58-kilodalton early protein. J Virol 69: 5304-5310, 1995.

24. Stenberg RM, Witte PR and Stinski MF: Multiple spliced and unspliced transcripts from human cytomegalovirus immediate-early region 2 and evidence for a common initiation site within immediate-early region 1 . J Virol 56: 665-675, 1985.
25. Terhune SS, Schröer J and Shenk T: RNAs are packaged into human cytomegalovirus virions in proportion to their intracellular concentration. J Virol 78: 10390-10398, 2004.

26. Bishop J, Morton J, Rosbach M and Richardson M: Three abundance classes in HeLa cell messenger RNA. Nature 250: 199-204, 1974

27. Wang SM, Fears SC, Zhang L, Chen JJ and Rowley JD: Screening polyd A/dT) ${ }^{-}$cDNAs for gene identification. Proc Natl Acad Sci USA 97: 4162-4167, 2000

28. Kapranov P, Cawley SE, Drenkow J, et al: Large-scale transcriptional activity in chromosomes 21 and 22. Science 296: 916-919, 2002.

29. Kerry JA, Sehgal A, Barlow SW, et al: Isolation and characterization of a low-abundance splice variant from the human cytomegalovirus major immediate-early gene region. J Virol 69: 3868-3872, 1995 .

30. Hassan-Walker AF, Cope AV, Griffiths PD and Emery VC: Transcription of the human cytomegalovirus natural killer decoy gene, UL18, in vitro and in vivo. J Gen Virol 79: 2113-2116, 1998.

31. Adair R, Liebisch GW and Colberg-Poley AM: Complex alternative processing of human cytomegalovirus UL37 pre-mRNA. J Gen Virol 84: 3353-3358, 2003.

32. Tenney DJ and Colberg-Poley AM: RNA analysis and isolation of cDNAs derived from the human cytomegalovirus immediate-early region at 0.24 map units. Intervirology $31: 203-214$, 1990.

33. Scalzo AA, Forbes CA, Smith LM and Loh LC: Transcriptional analysis of human cytomegalovirus and rat cytomegalovirus homologues of the M73/M73.5 spliced gene family. Arch Virol 154: 65-75, 2009.

34. Kotenko SV, Saccani S, Izotova LS, Mirochnitchenko OV and Pestka S: Human cytomegalovirus harbors its own unique IL-10 homolog (cmvIL-10). Proc Natl Acad Sci USA 97: 1695-1700, 2000.

35. Lockridge KM, Zhou SS, Kravitz RH, et al: Primate cytomegalovirus encode and express an IL-10-like protein. Virology 268: $272-280,2000$

36. Kondo $\mathrm{K}, \mathrm{Xu} \mathrm{J}$ and Mocarski ES: Human cytomegalovirus latent gene expression in granulocyte-macrophage progenitors in culture and in seropositive individuals. Proc Natl Acad Sci USA 93: 11137-11142, 1996.

37. Hutchinson NI, Sondermeyer RT and Tocci MJ: Organization and expression of the major genes from the long inverted repeat of the human cytomegalovirus genome. Virology 155: 160-171, 1986.

38. Greenaway PJ and Wilkinson GW: Nucleotide sequence of the most abundantly transcribed early gene of human cytomegalovirus strain AD169. Virus Res 7: 17-31, 1987.

39. Demarchi JM: Human cytomegalovirus DNA: restriction enzyme cleavage maps and map locations for immediate-early, early, and late RNAs. Virology 114: 23-38, 1981.

40. Black DL: Mechanisms of alternative pre-messenger RNA splicing. Annu Rev Biochem 72: 291-336, 2003.

41. Hastings ML and Krainer AR: Pre-mRNA splicing in the new millennium. Curr Opin Cell Biol 13: 302-309, 2001

42. Schwartz SH, Silva J, Burstein D, Pupko T, Eyras E and Ast G: Large-scale comparative analysis of splicing signals and their corresponding splicing factors in eukaryotes. Genome Res 18: 88-103, 2008.

43. Cartegni L, Chew SL and Krainer AR: Listening to silence and understanding nonsense: exonic mutations that affect splicing. Nat Rev Genet 3: 285-298, 2002.

44. Reed $\mathrm{R}$ and Maniatis $\mathrm{T}$ : Intron sequences involved in lariat formation during pre-mRNA splicing. Cell 41: 95-105, 1985.

45. Ruskin B and Green MR: Role of the 3' splice site consensus sequence in mammalian pre-mRNA splicing. Nature 317: 732-734, 1985. 